América sin nombre, n. ${ }^{\circ} 22$ (2017) 73-81

DOI 10.14198/AMESN.2017.22.06

ISSN: 1577.3442 / eISSN: 1989-9831

Fecha de recepción: 03/09/2017

Fecha de aceptación: 14/10/2017
Puede citar este artículo como:

Bolognese, Chiara. «El cuento cubano del siglo XXI en las voces de Ena Lucía Portela y Jorge Enrique Lage». El cuento hispanoamericano del siglo XXI. Agustín Prado Alvarado (coordinador). América sin Nombre, 22 (2017): 73-81, DOI: 10.14198/AMESN.2017.22.06

Link para este artículo: http://dx.doi.org/10.14198/AMESN.2017.221.06

\title{
El cuento cubano del siglo XXI en las voces de Ena Lucía Portela y Jorge Enrique Lage
}

\author{
Cuban short story in the 21 st Century: the voices \\ of Ena Lucía Portela and Jorge Enrique Lage
}

\author{
Chiara Bolognese* \\ Università di Roma La Sapienza
}

\section{Resumen}

En este artículo propongo, en primer lugar, una reflexión sobre la cuentística cubana contemporánea, trazando un panorama que empieza en los años Noventa - una época durísima en Cuba, por la caída del muro de Berlín y la disolución de la Unión Soviética- y llega hasta nuestros días. En segundo lugar, me concentro en el análisis de dos cuentos de dos voces imprescindibles de la narrativa actual, es decir Ena Lucía Portela y Jorge Enrique Lage, para mostrar las diferencias y las analogías que presentan sus propuestas literarias.

Palabras clave: Ena Lucía Portela; Jorge Enrique Lage; cuento; abyección; norma; Período Especial

\section{Abstract:}

In the first part of this essay, I will propose a reflexión on Cuban contemporary short stories, beginning with the cultural production following the Fall of the Berlin wall till nowadays. In the second part of it, I will analyze two short stories written by Ena Lucía Portela and Jorge Enrique Lage, who are two very important voices of contemporary Cuban narrative. I will investigate the differences and the analogies between their writing proyect.

Keyword: Ena Lucía Portela, Jorge Enrique Lage, short story, abyection, normativity, Special Period

\footnotetext{
* Chiara Bolognese es licenciada en Lenguas y Literaturas Extranjeras por la Università Cattolica de Milán, y doctora en Literatura Hispanoamericana por la Universidad Autónoma de Madrid. Ha sido becaria posdoctoral en el Centre de Recherches LatinoAméricaines de Poitiers, en la Universidad de Santiago de Chile y en la Universitat Autònoma de Barcelona. Actualmente es profesora de Literatura Hispanoamericana en la Universidad La Sapienza de Roma. Ha publicado artículos y ensayos autores chilenos, argentinos, venezolanos y cubanos; y es autora del libro Pistas de un naufragio. Cartografía de Roberto Bolaño.
} 


\section{Dos voces fundamentales de la cuentística cubana contemporánea: Ena Lucía Portela y Jorge Enrique Lage}

Desde hace unos años, la crítica que se ocupa de la narrativa cubana actual se está centrando en la cuentística y en la narrativa breve, porque es allí donde se encuentran las mayores novedades y las voces más interesantes, sobre todo si nos referimos a los escritores nacidos en la década del setenta y principios de los años ochenta. Este lapso temporal incluye a dos "promociones» ${ }^{1}$ diferentes, las cuales, junto a esas voces consideradas ya canónicas de la narrativa cubana, son las que están animando el debate cultural. Ambos grupos empezaron y siguen desempeñando una importante labor como cuentistas. La primera promoción, los que en su tiempo fueron llamados Novísimos, nacidos entre el 59 y el 72, se formó en los difíciles años de la crisis económica de los noventa; y la siguiente, la Generación 0 , conoció los duros momentos del Periodo Especial, pero ha entrado a la escritura ya en el siglo xxI, disfrutando por lo tanto de una mayor libertad. Esta diferencia influye mucho en su forma de concebir la literatura y en su producción.

Para que se entiendan mejor las problemáticas y los intereses de la narrativa cubana actual es necesario recordar la situación histórica, política y social en la que, aun estando en diferentes etapas vitales, se movieron estos autores.

Veamos pues, en breve, el recorrido que han llevado a cabo dichos escritores y qué eventos influyeron en su producción, para luego analizar más en detalle dos cuentos de dos figuras muy significativas de la actualidad cubana.

\section{La caída del muro de Berlín y su repercusión en el mundo cultural de la isla: la aparición de los Novísimos}

Es sabido que los años noventa, con la caída del muro de Berlín y la posterior disolución del bloque socialista, cambiaron para siempre la historia contemporánea. Cuba, por su cercanía política y dependencia económica de la Unión Soviética, vivió estos acontecimientos como un cambio dramático. La crisis

1. Salvador Redonet habla de promoción, en base a la fecha de publicación de sus primeros textos, y no de generación en base a la fecha de nacimiento (Redonet 20). financiera, que pronto se revelaría también social, moral y cultural, marcó definitivamente el curso de la Revolución y la existencia de los habitantes de la isla. Los noventa, sobre todo la primera mitad, fueron un momento de inflexión, y el derrumbe económico se transformó también en crisis ideológica. Es la época que Fidel Castro denominaría Periodo Especial en tiempos de paz.

Esta gran crisis se reflejó también en la producción literaria, ya que empezaron a proponerse nuevos temas y preocupaciones que siguen hasta el día de hoy. Este período marcó un antes y un después en la narrativa cubana contemporánea. $Y$ es que a pesar del dramático problema de la falta de papel, en esos años se dio también un fenómeno interesante desde el punto de vista cultural: la publicación de numerosas antologías que dieron voz a autores hasta aquel momento desconocidos, y que demostraron que, a pesar de todo, o tal vez justamente por esa situación, la vida cultural estaba en plena efervescencia.

El bullicio cultural y el deseo de crítica y de rebeldía tuvieron dos momentos muy representativos en los años 1990 y 1993. El primero es crucial porque se publica el relato «El lobo, el bosque, y el hombre nuevo» de Senel Paz, cuya versión cinematográfica titulada Fresa y chocolate será mundialmente conocida; en tanto que los jóvenes narradores Ronaldo Menéndez y Ricardo Arrieta reciben en Cuba el Premio David de cuento con la colección titulada Alguien se va lamiendo todo. Estas publicaciones marcan un corte con la producción anterior (López Sacha 254) y sacan a colación temas antes tabú que se convertirían en fundamentales. El segundo, 1993, es central porque aparece la antología titulada Los últimos serán los primeros, que fue un «terremoto» (Strausfeld 12) en el mundo editorial cubano, ya que el prologuista y antólogo Salvador Redonet habla por primera vez de los que bautiza como Novísimos, la primera generación nacida y formada tras el triunfo de la Revolución, y que se abre a la literatura en ese momento de gravísima crisis. Algunos de los antologados son voces imprescindibles de la actualidad; me refiero, en particular, a Ena Lucia Portela, Ronaldo Menéndez, Alberto Garrandés, pero también a José Miguel Sánchez-Yoss-, Daniel Díaz Mantilla, entre otros.

Este grupo propone historias con personajes desdibujados, que habitan el mundo marginal, y viven en la angustia y la soledad. La variedad en la producción y las técnicas narrativas de los Novísimos es sorprendente: se va desde lo existencial hasta la violencia y el realismo sucio, a través de la fabulación, 
la parodia, el pastiche, la celebración de los rockeros, entre otras posibilidades. Sus cuentos trascienden la estructura dramática tradicional: ya no se trata de una suma de sucesos que crece hacia el desenlace, sino que se busca subvertir las categorías narrativas de autor, narrador, personaje, entre otras (cfr. López Sacha 56).

Los Novísimos se alejan de las consignas de la cultura revolucionaria y también de la denuncia del desencanto que se podía apreciar en algunos escritores de la generación anterior (piénsese, por ejemplo, en Leonardo Padura), ya que nunca realmente vivieron el encanto (Fornet Los nuevos paradigmas 90), en tanto que se fueron acercando a las preocupaciones de sus contemporáneos latinoamericanos. El tema de la Revolución tal y como había sido tratado hasta entonces va desapareciendo y, cuando está presente, sólo representa el telón de fondo para poder contar las vidas de unos personajes derrotados.

Margarita Mateo Palmer (Anales 52) evidencia asimismo que los Novísimos dan por sentado (y en esto radica una interesante diferencia con respecto a los que vienen después ${ }^{2}$ ) que existe un abismo entre la historia oficial y la historia real, lo que con frecuencia recrean en sus novelas, a veces a través de la denuncia dramática, otras llevando a cabo una indagación desenfadada llena de ironía, que ridiculiza el pasado histórico.

Por otra parte, hay otros aspectos que caracterizan a los Novísimos y se vinculan a la propuesta de la promoción que los sigue, con la que establecen un diálogo fecundo. En primer lugar, es de destacar el fuerte deseo de proponer un cambio de centro: los Novísimos reivindicaron con orgullo la marginalidad con respecto al mundo cultural de la época y propusieron reafirmar la diferencia: se trató de un ataque al poder por parte de la periferia (cfr. Rubio Cuevas), algo que siguen haciendo en sus textos más recientes, pero ya no desde la periferia, sino desde una posición de intelectuales consolidados. Estos autores rescataron, pues, a los personajes marginales, logrando que su condición se convirtiera en el eje de sus proyectos, y, por ende, en el centro y protagonista de la narrativa cubana de los últimos veinte años. En este sentido, Margarita Mateo los define como habitantes de un espacio llamado Marginalia (Ella escribia poscrítica 176-177). Y desde Marginalia

2. Me parece que los escritores de la Generación 0 ya ni se interesan por esta dicotomía. hablan las dos voces de los cuentos que se verán en las páginas que siguen.

\section{Entrando en el nuevo milenio: la Generación 0}

El ingreso en el siglo XXI en Cuba coincidió con cierta mejora de la situación económica debida, entre otras razones, al nuevo rumbo político muy prometedor tomado por importantes países aliados potenciales de Cuba como Venezuela, Argentina, Bolivia e incluso China. Asimismo, es necesario mencionar algunos eventos que ya son hechos históricos fundamentales, como el 17 de diciembre de 2014, cuando se dio el anuncio de la reanudación de las relaciones diplomáticas entre Cuba y Estados Unidos; y, aunque tal vez influyan más desde el punto de vista del imaginario que desde el concreto, otros dos particularmente relevantes: la visita de Barack Obama en marzo de 2016 y la muerte de Fidel Castro el 25 de noviembre del mismo ańo. Las implicaciones de estos últimos todavía no se han podido ver en la producción literaria, más allá de algunas declaraciones de escritores en entrevistas, blogs, etc.

No obstante, sin duda el comienzo del nuevo siglo ve cómo la producción cultural se va enriqueciendo, y empieza a ser protagonizada por un grupo bastante heterogéneo de escritores y artistas denominados Generación 0. Se trata de jóvenes que escriben tras el (supuesto) fin del Periodo Especial en torno al ańo 2000, influidos por las redes sociales, la tecnología y que, por diferentes razones, tienen más conocimiento de la realidad fuera de la isla. Todos estos elementos influyen en la propuesta de mundo que ellos quieren transmitir. Fundamental para la elaboración de su estética es el hecho de vivir en un espacio conectado o vinculado a la red. Las urgencias ya no son las de los años ochenta y noventa, puesto que los problemas y las posibilidades han cambiado y para estos jóvenes el objetivo principal de su arte es lograr establecer un diálogo con el presente, que trascienda las fronteras nacionales. Para eso tal vez el cuento, y más cuando se publica también en la red, resulte un género más práctico y eficaz.

En estas nuevas producciones desaparece la referencia directa a las penurias económicas, en tanto que se sigue profundizando en la reflexión sobre identidades marginales que se arrastran por ciudades que pueden ser, o no ser, y eso ya ni siquiera es relevante, La Habana. Se pasa, entonces, a una literatura que indaga sobre el ser humano desde el punto de vista individual, dado que el sujeto colectivo 
propuesto por el proyecto revolucionario ya parece haber dejado de existir.

Estos autores van abriendo un espacio diferente, el del diálogo con el extranjero. El mundo fuera de Cuba queda más accesible; puesto que, por un lado, hoy para los cubanos es más fácil viajar gracias a la abolición del permiso de salida; por otro, éstos pueden emprender el viaje virtual, gracias a la mayor facilidad de conexión a internet. Este nuevo territorio sigue siendo, sin embargo, el espacio de la decadencia y de la resistencia -que ya describieron Portela y Menéndez, entre otros-, y, al mismo tiempo, el de las redes sociales, de internet que acerca personas, culturas y países, en tanto que desde él se sigue llevando a cabo una fuerte crítica. Una crítica que, hoy en día, ya no se dirige sólo a la realidad cubana, y, cuando lo hace, se trata de una sociedad en la que el papel de la Revolución ya ha perdido todo el interés como tema y como preocupación. Si ya los Novísimos, en palabras de Jorge Fornet, llevaban a cabo una "escritura posrevolucionaria" pues «la revolución [...] se hacía casi invisible en sus páginas» (Elogio de la incertidumbre 155), éstos hacen una escritura a-revolucionaria, ya que la Revolución en cuanto tal está prácticamente ausente, si acaso es ridiculizada como algo que pertenece a un lejano pasado, en tanto que abarcan en su nuevo horizonte de referencia a otras sociedades, y entre ellas, en particular, la norteamericana.

Una vez más, son algunas antologías las que tienen un papel muy importante a la hora de dar a conocer la producción de estos jóvenes escritores dentro y fuera de la isla. Hay varias, y entre ellas dos se revelan imprescindibles en cuanto a la legitimación internacional: Malditos bastardos. Diez narradores que no son Pedro Juan Gutiérrez ni Zoé Valdés ni Leonardo Padura ni... (Madrid 2014), compilada por el cubano Gilberto Padilla Cárdenas, y Nuevarrativa cubana: una antología de literatura emergente, hecha por Orlando Luis Pardo Lazo (2013), aparecida online simultáneamente en castellano y en inglés 3 , por Sampsonia Way ${ }^{4}$, un portal web creado en Pittsburgh para favorecer los intercambios culturales y para dar voz, según dice, a los escritores perseguidos ${ }^{5}$, la cual tiene también una versión

3. Para la mayoría de los antologados es la primera aparición en este idioma.

4. http://www.sampsoniaway.org/features/2013/08/06/ antologia-nuevarrativa-cubana/

5. Patrocinada por City of Asylum, una organización con sede en Pittsburgh que nació para apoyar a los escritores impresa titulada Generation Zero. An Anthology of New Cuban Fiction.

Los dos títulos son muy elocuentes de lo que se espera de los nuevos narradores o de lo que ellos mismos quieren hacer. En la primera, desmarcarse de los más conocidos, leídos y valorados -sobre todo en el extranjero-, y ubicarse en un lugar nuevo desde el que hablar; los «malditos bastardos» se definen por negación (negación de los "padres», cuya herencia no quieren recoger). En la segunda, se comprende su voluntad de situarse en un mundo que ya no ve a EEUU como el enemigo y vincularse de diferentes formas al universo de Internet y de la globalización, para alcanzar también a un público lo más amplio posible.

Estas dos antologías, en cierto sentido, quieren establecer el nuevo canon de la literatura cubana de hoy y del futuro. Los nombres en buena parte coinciden: Nuevarrativa cubana incluye a ocho de los diez de Malditos bastardos... (faltan Legna Rodríguez y Anisley Negrín). Se trata de nombres que encuentran sus elementos de unión en la voluntad de hacer cultura a través de varios medios y soportes; el hecho de haber vivido los años 0 en la Isla, y el haber nacido a la escritura en esa fecha. Cabe agregar, además, que para una reflexión más exhaustiva a éstas habría que añadir ${ }^{6}$ la antología de Caridad Tamayo, publicada en Cuba, titulada Como railes de punta (Santa Clara 2013), aunque incluya a narradores nacidos solo a partir de 1977 (entre ellos Jorge Enrique Lage y Raúl Flores, quienes son los únicos que aparecen en las tres).

Aunque la idea es atractiva, la propuesta de que estos autores son marginados, excluidos y censurados no se ajusta del todo a la realidad. Viven una tensión con un modelo de sociedad que no los complace y del que, sin embargo, toman aquello que les puede ser útil, incluyendo las opciones editoriales y los premios literarios. Son ellos, pues, los que se están haciendo ahora con los más importantes galardones en Cuba: Ahmel Echevarría acaba de ganar el Alejo Carpentier 2017, además del David que le otorgaron

perseguidos por sus ideas, después de que Salman Rushdie empezara a sufrir la persecución debido a su novela Los versos satánicos (http://cityofasylum.org/about/history/). Entre los escritores latinoamericanos apoyados por esta asociación están Horacio Castellanos Moya, Israel Centeno y Orlando Luis Pardo Lazo.

6. Véase también Cuba in Splinters. Eleven Stories from the NewCuba, O.L. Pardo Lazo, New York y Londres, O/R Books. 
en 2004 y el Italo Calvino en 2012; Jorge Enrique Lage recibió el Premio Calendario en 2003 y en 2004, Legna Rodríguez lo recibió en 2008, al que añade el Iberoamericano de cuento Julio Cortázar en 2011 y el Casa de las Américas de teatro en 2016.

Por otra parte es obvio que proponerse en EEUU como los censurados de la «Cuba castrista» puede despertar cierto interés; sin embargo la realidad es que, a diferencia de los escritores que los precedieron, éstos entran y salen del país libremente y se mueven en el mundo cultural de la Isla sin demasiadas dificultades, por un lado con el deseo de pertenecer a ese espacio (que proporciona premios, legitimación, visibilidad, posibilidad de publicación), por el otro con la voluntad de desestabilizarlo y sacudirlo.

Los cuentos de los miembros de la Generación 0 describen un universo que es a un tiempo cubano -los creadores son cubanos y la ciudad de La Habana frecuentemente está presente como escenario o en el imaginario de los protagonistas-, y también transnacional, ya que une o pone a dialogar países. Se llega incluso a proponer un espacio cubano que también se puede ubicar fuera de la Isla (por ejemplo, el cuento de Lage "Fuera del juego" o el de Pardo Lazo "Cuban American Beauty", recogidos en las antologías citadas), cuando los protagonistas son originarios de la isla, pero han dejado el país. Se hace evidente, además, que este nuevo territorio cubano limita cultural y lingüísticamente con el mundo anglosajón, que bebe de él (piénsese en la colección de cuentos Vultureffect, de Lage, por ejemplo), al tiempo que, ellos, desde la isla, quieren establecer un dialogo enriquecedor con el otro lado del mar. Reformulan así, en términos de pertenencia y referentes, la identidad nacional, que deja de ser solo nacional y se convierte en global.

\section{Continuidades y diálogos: «Al fondo del cementerio» (Portela, 1999) y "Las hermosas vísceras de Alicia en las paredes y el techo» (Lage, 2007) $)^{7}$}

Esbozadas las poéticas de las dos promociones, cabe señalar también que la lectura de los cuentos de estos autores muestra, además, muchos elementos

7. Estos cuentos no están en las antologías que he mencionado en las páginas anteriores, pero me parece que ilustran bien algunas temáticas fundamentales y las peculiares formas de tratarlas de los autores. de continuidad entre ellos en ciertas temáticas y en las maneras de abordar la reflexión sobre la sociedad cubana. Como se ha dicho, es fundamental, en este sentido, la vinculación al universo de la marginalidad, recreada a través de historias de abyección, de cuerpos violados (véase Lage con sus «Breaking news» y «Fuera del juego»), descritos con realismo violento. En este mundo de la marginalidad, los protagonistas son sujetos solos, que no encuentran apoyo en nadie, en ningún tipo de relación afectiva, ni, mucho menos, en el Estado, que ahora es distante o ausente. Veamos, pues, algunos ejemplos concretos en las voces de dos autores imprescindibles de este nuevo siglo.

Ena Lucía Portela y Jorge Enrique Lage son escritores pluripremiados. A través de su trabajo contribuyen a trastocar los criterios y valores dictados por la Revolución, en tanto que hacen tambalear el concepto de «norma» y han contribuido a que el cuento siga siendo uno de los géneros más relevantes en la literatura cubana actual.

Los dos textos que se analizarán son relevantes porque muestran que sus autores, manteniendo claramente sus diferencias en estilos y propuestas, elaboran en ańos diferentes -un desfase temporal de ocho años, pero ambos tenían 27 años cuando éstos vieron la luz- dos propuestas que dialogan entre sí, que se refieren a los mismos años -la última década del siglo xx-e ilustran bien sus respectivas poéticas.

Lo primero que llama la atención son los elementos comunes entre las tramas: en el cuento de Portela, dos hermanos poco más que adolescentes, Lavinia y Lisandro, abandonados por sus padres, arrastran sus días entre noches de amor incestuoso en el cementerio y existencias sin perspectivas en su casa, invadida por las cucarachas. Un día llega el fumigador que quiere liberarlos de los incómodos animales, y ellos se resisten. El cuento de Lage relata un encuentro entre dos amigos escritores en una casa invadida por las salamandras. Éstos, mientras intentan matar a los animales cocinándolos, rememoran a través de unas fotos un episodio en el que una amiga del grupo explotó, embarrando con sus vísceras las paredes de la casa.

La analogía temática, por un lado, muestra cierto espíritu generacional, en el deseo de pintar el horror con un estilo que se acerca al cine gore; por otro lado, se propone como un interesante recurso para llevar a cabo una denuncia social parecida.

Ambos textos presentan las características de los que se definieron «cuentos frikis» (Martín Sevillano 
$310)^{8}$, considerados como cuentos testimoniales, un género novedoso en la narrativa cubana de la época, ya que éste deja de ser el testimonio militante de la izquierda de los setenta, y se pasa a abordar los conflictos de la situación social -no pocas veces grotesca- de la Cuba de los noventa. Son cuentos que proceden de la «marginalia social» (Menéndez 220), la que cobija a los drogadictos, los gays, los rockeros, los jineteros, entre otros. Es una escritura testimonial transgresora, que avisa de la existencia de otras costumbres sociales, formas de vida, otros «hábitos existenciales» (Menéndez 220).

Un primer aspecto interesante es el hecho de que los protagonistas son seres marginales, pero extraordinariamente sabios, lo que hace que su marginalidad sea peculiar, pues la gran cantidad de referencias cultas que dominan les permite cierto rescate social. En ambos, la soledad, la apatía y la frustración son evidentes; y la única vía de escape es, tal vez, la posibilidad de hablar a través de la literatura, es decir la de construirse un mundo literario: produciéndola en el caso de Lage, ya que los dos protagonistas son escritores; citándola y asimilándola en el de Portela, en donde la protagonista lee su vida a través de los cuentos de algunos de los más importantes escritores del siglo xx (Kafka y Cortázar, en particular). Y es que uno de los temas de estos cuentos es el retrato de la frustración de unos jóvenes que hablan a través del arte y la literatura. Una frustración que lleva a los personajes al desequilibrio psíquico. Lo sucio, lo grotesco, lo decadente se fusionan con la a-normalidad de los personajes. Estos juegan con la vida y la muerte, mejor dicho, se mueven entre vida y muerte, siendo prácticamente muertos en vida.

Es evidente que los autores proponen una escritura de la crisis: los protagonistas son individuos sin proyección hacia el futuro. Se trata de una ausencia de futuro que se ve más clara en Portela que en Lage (cuyos personajes sí tienen planes); más clara alrededor de 1999 que en 2007, cuando la situación económica se iba haciendo más prometedora.

Estos dos cuentos, además, giran alrededor de dos ejes muy fecundos y en cierto modo constantes en la cuentística del nuevo siglo: la abyección y la (violación de la) norma.

8. Ana Belén Martín Sevillano sigue desarrollando sus reflexiones sobre estos temas en su libro Sociedad civily arte en Cuba: cuento y artes plásticas en el cambio de siglo (1980-2000). Madrid: Verbum, 2008.

\section{Escribir la abyección ${ }^{9}$}

Como bien dice Iraida López (xxiii), Portela, con frecuencia, nos presenta a personajes que nos hacen sentir incómodos ${ }^{10}$. Lage en muchos de sus cuentos $^{11}$, y en éste en particular, lleva a cabo una propuesta parecida. El lector se tiene que confrontar con lo abyecto (las cucarachas y las salamandras, respectivamente) y con individuos que nos muestran el lado maligno y perverso del ser humano (López xxiii). Así se describen los personajes de Portela: un joven envejecido y marchito (11), «un cadáver viviente» (11) «un lamentable despojo» (11); se trata de una cofradía de abyectos (Portela 26). Incluso, en Portela, Lavinia a veces siente «deseo de asimilarse a las piedras, a las losas rotas, a los vanos conjuntos de mármol y bronce allí enfrente» (19); en tanto que uno de los protagonistas de Lage amenaza con abrirse la cabeza si no le abren la puerta (9).

Ambos cuentos se caracterizan por la atmosfera de muerte y por las constantes referencias al cementerio: los jóvenes juegan en el cementerio en donde se llenan los bolsillos de cucarachas (Portela 15-16), las cuales abusan de ellos (15); análogamente el personaje de Lage se queja porque sufre "una racha de dolor de espalda por estar durmiendo en ataúdes» (10). Los dos cuentos nos hablan desde el cementerio: la muerte siempre está al acecho.

Y si en Portela los personajes «simplemente rechaza[ba]n la vida social» (15) y viven y disfrutan de su abyección; en Lage se propone una relación que tiene todavía algunos elementos de cercanía a la norma. En él, pues, los personajes perciben que no están bien y que hay algo trastocado en su cuerpo y en su mente. El protagonista lo asume cuando toca la puerta con la cabeza: «A cabezazos. Nadie me abría. Toc toc toc más fuerte. Tenía que remover unas cuantas cosas de allí dentro (la cabeza). Por ejemplo: unos ojos que no eran mis ojos» (7) y, además, es un cuerpo que antes funcionaba, ya que recuerda que la primera vez lo hizo con los nudillos «suavemente,

9. Julia Kristeva en Poteri dell'orrore: saggio sull'abiezione habla de lo abyecto como de lo que perturba una identidad, un sistema, un orden. Lo relaciona con lo que no respeta los límites, es decir lo ambiguo, lo mixto.

10. Sobre este tema, cfr. el artículo de Mayerín Bello Valdés «De Ena Lucía Portela Ad Ephesĭos». Mitologías hoy, 10, (2014): 129-137 Disponible en: <http://revistes.uab.cat/mitologias/ article/view/v10-bello/148>.

11. «Fuera del juego», por ejemplo. 
como lo hacen las personas que derrochan decencia, civismo, democracia» (7). Ellos no fomentan la abyección; los que lo hacen son las salamandras y el personaje de Alicia, que da el título al cuento, y que «es siempre esa muñeca-imagen tan singular [...] que amenaza convertirse ella sola en un género, un post-algo, una nueva forma» (16), y que sí se convierte en una nueva forma, cuando explota y deja a todos embarrados: no sólo las salamandras sino también las vísceras de una amiga ensucian el piso, convirtiéndolo en abyecto.

En ambos cuentos la abyección se representa también a través de cuerpos mutilados: en Lage el cuerpo humano explota; en Portela, el ojo humano, sacado de su cuerpo, vigila a los protagonistas. Además, los cuerpos de los animales son convertidos en pulpa: en Portela la protagonista aplasta a unas cucarachas en un arrebato (20); mientras que los personajes de Lage las cuecen y se las beben haciéndose ellos mismos una cosa sola con la abyección.

\section{Personajes vigilados y fuera de la norma ${ }^{12}$}

Considerado el aislamiento en el que viven los protagonistas de los dos cuentos, es interesante reflexionar sobre qué tipo de contacto establecen éstos con el mundo exterior; y qué relación tienen con las figuras o los elementos que de alguna forma representan cierta normalidad y/o norma, es decir el fumigador en el cuento de Portela y los jóvenes que aparecen en el conjunto de fotos que observan los protagonistas en Lage.

Además, en ambos cuentos, la mirada ejerce un papel fundamental. El ojo que aparece en el cuento de Portela es casi un protagonista más, que causa en los personajes la sensación de que alguien los vigila: «de repente, el muchacho se sintió espiado» (29). El fumigador y el ojo establecen una doble norma, un doble control en el cuento de Portela; en tanto que en Lage, el protagonista quiere quitarse unos ojos que no son suyos y que hacen que se sienta observado (7). Puede interpretarse que en ambos textos los ojos aluden al control estatal y social: el ojo representa la actividad de vigilar.

En los dos relatos tenemos ojos que, como sea, no le pertenecen a nadie: en Lage se observa que

12. Cfr. Michel Faucault Vigilar y castigar. Madrid: Siglo xxI, 2012 y Los anormales. Buenos Aires: Fondo de Cultura Económica, 2000. «sus ojos siguen ahí cuando cierras los ojos» (11), se trata, pues, de una mirada que analiza sin que los personajes puedan substraerse a ella; en Portela se humaniza un ojo en formol que los protagonistas guardan con infinito cariño, y que los observa y acompaña en sus días: el ojo se convierte así en el segundo elemento normativo, después del fumigador (30).

Los dos textos transmiten una fuerte sensación de encierro: no hay -o se rechaza- comunicación con el afuera; y cada autor logra esto de forma diferente. Los personajes de Portela son «Moscas atrapadas en una telaraña, marionetas dirigidas por un dios loco» (27). Su único contacto con el mundo exterior es a través del fumigador que quiere normalizarlos -la norma, el bien, la limpieza se encarnan en un funcionario del Gobierno, en tanto que ellos violan la ley al no permitirle entrar (Portela 26)-. En Lage no hay realmente un personaje normativo que vigile a los demás. Aquí el mundo real y normado aparece a través de la observación de algunas fotos del pasado de los personajes, una acción que los devuelve a una época de mayor despreocupación e ilusión, que ya es sólo un recuerdo.

La diferente relación con los animales también es interesante desde este punto de vista: mientras que Adriana quiere matar a las salamandras; Lavinia protege a sus cucarachas: Adriana mantiene cierto contacto con la norma (a pesar de la ausencia de alguien que la encarne), la que en Portela está totalmente eliminada (a pesar de la presencia del personaje normativo). Mientras que en Lage se quiere un "territorio libre de anfibios» (15); en Portela la vida de los jóvenes transcurre en completa simbiosis con los insectos. La existencia en el mundo abyecto en Portela se convierte en un relato de amor repugnante, pues las cucarachas son consideradas como parte de la familia, positivas, hasta humanizadas:

Mire usted como la puso con sus amenazas. Pobrecita [...] la mujer besó a la cucaracha del mismo modo que se besa al bebé enfermo o al amante moribundo, le prodigó algunas caricias también impregnadas de esa fragilidad esencial [...] le dijo mi chiquitica y por fin la colocó en el suelo con la mayor delicadeza del mundo (18).

Una humanización que no se da en las salamandras de Lage, quien retrata una vida apagada, en la que incluso los planes que tienen los protagonistas parecen inútiles y frustrados desde el principio. 


\section{Algunos elementos comunes}

Estos cuentos, a pesar de sus diferencias en el tratamiento de los aspectos antes señalados, muestran numerosos elementos de continuidad. Sus protagonistas son marginales, locos, excéntricos e increíblemente cultos. Se muestra aquí que es posible acceder a la cultura y producirla desde cualquier lugar y posición social. Ambos autores reivindican la posibilidad de hablar desde lo abyecto.

Describen, asimismo, un mundo cerrado, metáfora de una sociedad apagada, que ahoga. Nos estamos moviendo en unos espacios violados. En Portela, los animales penetran en la casa, irrumpen en la tranquilidad del hogar; las cucarachas y, más aun, el amor que la protagonista les profesa rompen la normalidad y la cordura. En Lage también el espacio es profanado, ensuciado por la presencia de las salamandras y, tiempo atrás, por la explosión del cuerpo de una muchacha del grupo. La amenaza, lo abyecto, lo grotesco están representados por los animales; los que, además, tienen la función de indicar una presencia que desde fuera invade la esfera de lo privado, y que quiere imponerse e imponer sus leyes.

En Portela, lo más importante es proteger el mundo íntimo que puede dejar de existir, amenazado por la invasión de las cucarachas, y, más aun, por la insistencia del fumigador y por el ojo en formol que vigila; en Lage se denuncia la falta de futuro y la necesidad, más fuerte que cualquier otra, de contar «a fin de cuentas se trata de eso: remover, abrir, romperte la cabeza, y no importa que no haya sucedido así o que no haya sucedido nada: de todas formas había que contarlo» (Lage, 21).

Claramente los dos cuentos quieren describir una sociedad en decadencia, donde lo abyecto y el horror se han apoderado de los espacios y de la vida de los protagonistas, quienes, para más inri, permanecen indiferentes a lo que acontece.

Los escenarios en los que se desarrollan los hechos pueden ser entendidos como una alegoría de La Habana de nuestros días, en la que, según denuncian ambos autores, lo grotesco y lo monstruoso son parte de la vida cotidiana, una vida que se desarrolla al compás del recuento de las salamandras que van al cubo, en Lage; y en Portela está marcada por las visitas del fumigador.
Los cuatro personajes ejercen una crítica pasiva y no violenta, siendo ellos mismos víctimas de su condición existencial de miseria y soledad. No se alinean al modelo propuesto por la Revolución, pero tampoco se presentan como antimodelos o como disidentes. Su disconformidad se lleva a cabo más bien a través de la apatía. Se desvinculan de la norma, y a partir de su diferencia de ella se construyen una identidad propia. Son sujetos que, al fin y al cabo, se sienten cómodos en la abyección, ellos mismos se autorrepresentan como abyectos: pero en Portela esta autorrepresentación funciona, es positiva, ya que los personajes están satisfechos con ella; mientras que en Lage esto no ocurre y ellos simplemente se sienten desubicados.

La abyección es, por otra parte, lo que los obliga a actuar y a establecer un contacto con el exterior, encarna la amenaza, pero también el pretexto para actuar. Sin animales los personajes se hundirían en la apatía más completa; los «bichos» son la vida, abyecta, ella también.

Es de notar, además, que ya sin animales ambos cuentos representarían una reflexión sobre cuerpos y personajes marginales, destrozados, muertos en vida; con la presencia de ellos esto aumenta exponencialmente. Las cucarachas y las salamandras marcan espacios de perversión, al tiempo que señalan como abyectos a los personajes que con ellos comparten sus días.

La resistencia a los animales se puede leer como una metáfora de un intento de resistencia social, ya que estas criaturas incontrolables que llegan a todos los lugares pueden representar una alusión a cierto control estatal. Los bichos encarnan la opresión -ya que invaden- pero también permiten la resistencia, pues con, o a pesar de ellos, los protagonistas van arrastrando su existencia.

Estos dos cuentos, con sus diferentes maneras de reflexionar sobre la abyección y la (a) normatividad, no son sino unos ejemplos de que la "cohabitación» de grupos de escritores diferentes logra establecer un intercambio fecundísimo, ya que todos están produciendo y marcando las nuevas direcciones de la narrativa cubana actual, en la cual centro y margen dialogan, en la cual se habla y se contribuye al debate intelectual desde diferentes países y posturas, y donde los intereses de los autores muestran un abanico muy amplio. Ahora solo hay que seguir leyendo para ver cómo desarrollarán sus propuestas. 


\section{Bibliografía}

ForNet, Jorge. Los nuevos paradigmas. La Habana: Letras Cubanas, 2006.

Fornet, Jorge. Elogio de la incertidumbre. La Habana: Ediciones La Unión, 2014.

Kristeva, Julia. Poteri dell'orrore: saggio sull'abiezione. Milano: Spirali Editore, 1981.

LAGE, Jorge Enrique. «Las hermosas vísceras de Alicia en las paredes y en el techo". El color de la sangre diluida. La Habana: Letras Cubanas, 2007: 7-21.

López, Iraida. «Prólogo». El viejo, el asesino, yo y otros cuentos. Doral. FL: Stockcero, 2009: vii-xxv.

López Sacha, Francisco. Pastel flameante. La Habana: Letras Cubanas, 2006

Martín Sevillano, Ana Belén. Cuento cubano actual (1985-2000). Tesis doctoral (Universidad Complutense de Madrid 2005): 31 http://eprints. ucm.es/4831/1/T25953.pdf

Mateo Palmer, Margarita. "La narrativa cubana contemporánea: las puertas del siglo XXI». Anales de Literatura Hispanoamericana, 31, (2002): 51-64.
Mateo Palmer, Margarita. Ella escribia poscrítica. La Habana: Letras Cubanas, 2005.

MenÉndeZ, Ronaldo. «El gallo de Diógenes». Encuentro de la cultura cubana, 18, (2000): 215-222.

Padilla Cárdenas, Gilberto. (ed.). Malditos bastardos. Diez narradores que no son Pedro Juan Gutiérrez ni Zoé Valdés ni Leonardo Padura... Madrid: La Palma, 2014.

Pardo Lazo, Orlando L. (ed.). Nuevarrativa cubana: una antología de literatura e-mergente 2013. http:// www.sampsoniaway.org/literary-voices/2013/07/29/ generacion-cero-nuevarrativa-en-la-literatura-cubanae-mergente/

Portela, Ena Lucía. «Al fondo del cementerio». El viejo, el asesino, yo y otros cuentos. Doral. FL: Stockcero, 2009: 11-32. $1^{\text {a }}$ ed. 1999.

Redonet, Salvador (ed.). Los últimos serán los primeros. La Habana: Letras Cubanas, 1993.

Rubio Cuevas, Iván. «La doble insularidad de los novísimos narradores cubanos»: http://www.biblioteca.org. ar/libros/155192.pdf

Strausfeld, Michi (ed.). Nuevos narradores cubanos. Madrid: Siruela, 2000. 